\title{
Povos, Estados E Insurgência Islâmica Na África
}

\author{
Herbert EKWE-EKwe
}

Resumo: O autor reflete sobre a incapacidade do Estado na África em prover segurança e fornecer serviços sociais básicos à maioria da população. Argumenta que o "Estado de Berlim" pós-conquista europeia está sob crescente pressão de povos ou nações que desejam se tornar independentes. O mundo terá que lidar com um mapa da África em constante mutação, baseado nos movimentos de independência, que não são em essência islâmicos.

Palavras-chave: Estado de Berlim; África; Movimentos de Independência; Insurgência Islâmica

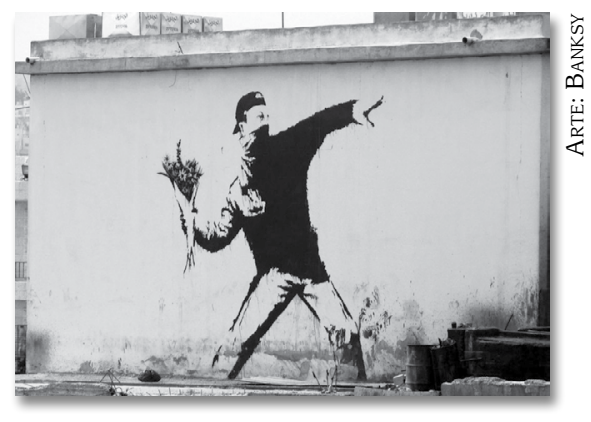

\section{Peoples, States And Islamic} Insurgency In Africa

\section{Herbert EKWE-EKWE}

Pesquisador independente na área de relações internacionais, especialista em genocídios, conflitos e guerras na África pós-colonial.

hekweekwe@hotmail.com
Abstract: The author discusses the African States' inability to provide security and basic social services to the majority of the population. He argues that the "State of Berlin" created by the European conquest is still under the growing pressure of peoples or 'nations' that want to become independent. The world will have to deal with an African map in constant change based on independence movements that are not Islamic in essence.

Keywords: Berlin State; Africa; Independence Movements; Islamic Insurgency

RECEBIDO EM $17-04-2015$

APROVADO EM $12-05-2015$ 


\section{INTRODUÇÃO}

África: Que época! No início de janeiro de 2015, os insurgentes islâmicos do Boko Haram, ao norte da Nigéria, assassinaram 2 mil crianças, mulheres e homens, aumentando exponencialmente a crueldade e selvageria que têm sido as marcas desta organização. Uma época em que o Al-Shabaab, um grupo somali, expande seus campos de assassínios no Quênia, os quais já duram quase uma década; em que centenas de outros africanos que almejam emigrar para a Europa se afogam no Mediterrâneo; inúmeros africanos de outros países, que não a África do Sul, estão sendo assassinados por seus anfitriões sul-africanos; em que diversos africanos são assassinados no Burundi por lideranças, generais e subalternos das forças do regime em exercício, empenhados em mais uma trágica e prolongada luta com a finalidade de confiscar o poder do Estado em algum lugar da África...

Enquanto o mundo testemunhava as ações do Boko Haram e o ataque ao Charlie Hebdo, em Paris, nos primeiros dias de 2015, e constatava também que raras foram as vezes em que dois massacres tão aterradores viessem a ocorrer ocorreram de maneira quase simultânea, em dois continentes diferentes, levados a cabo por duas organizações que certamente operavam de maneira autônoma, embora pertencendo à mesma agência político-religiosa global. Como já citamos, o Boko Haram, grupo islâmico insurgente sediado no norte da Nigéria, massacrou 2.000 pessoas em Baga (MARK, 2015), em apenas dois dias. Em Paris, num período de dois dias, na mesma semana, uma célula afiliada a alguma brigada de um califado islâmico com sede na França massacrou 17 pessoas, incluindo cartunistas de um jornal satírico, o Charlie Hebdo, além de funcionários e freqüentadores de um supermercado judaico.

O Boko Haram é ideologicamente ligado a causas islamitas globais e a projetos originados no Oriente Médio, incluindo a Al-Qaeda, na Península Arábica, e o Estado Islâmico (EI), que controla vastas faixas territoriais no Iraque e na Síria; bem como ao Talebã, no Afeganistão, e à Al-Qaeda do Magrebe islâmico (oeste/noroeste da África) e ao Al-Shabaab, na Somália. O líder do Boko Haram, Abubakar Shekau, nunca se cansa de enviar mensagens de solidariedade a essas organizações parceiras, através da 
publicação regular de vídeos que atualizam os objetivos estratégicos e as expectativas da insurgência transnacional em curso. Desde então, o Boko Haram se aliou formalmente ao Estado Islâmico, se auto-intitulando o equivalente árabe do califado do oeste da África.

As respostas da Nigéria e da França a essas tragédias, no entanto, não poderiam ter sido mais diferentes. Desde o início, o Estado francês saiu vigorosamente em defesa de sua população: mobilizou uma ampla parcela de suas forças de segurança para caçar e deter a célula assassina; aumentou a segurança de seus cidadãos ao mesmo tempo em que os tranquilizava, atendia a seus mortos, agonizantes e feridos; e organizou uma marcha solidária em honra aos 17 mortos e suas famílias, e pela reafirmação dos princípios cruciais e do ethos que sustentam a existência da república francesa. Três milhões e meio de pessoas se reuniram em Paris, no domingo, dia 11 de janeiro, para essa marcha histórica. Os chefes de Estado ou de governo de vários países do mundo europeu e de outros continentes compareceram à marcha em apoio à França. A mídia global deu cobertura minuciosa a tais acontecimentos durante uma semana.

\section{SILÊNCIO MÓRBIDO}

Na Nigéria, em contraste ao que ocorreu na França, a liderança do regime e suas instituições mantiveram um silêncio mórbido em relação à atrocidade que ocorreu em Baga - nenhuma palavra do atual chefe do governo ou de seus sete antecessores. Nenhum dos oito se comoveu a agir em defesa de Baga contra seus conhecidos agressores, nem mesmo diante do assombroso e minucioso relato feito por um chefe distrital de Baga, Baba Abba Hassan, que sobreviveu ao massacre e relatou logo depois: "[...] a maioria das vítimas é de crianças, mulheres e idosos que não conseguiram correr suficientemente rápido quando os insurgentes invadiram [...] utilizando lançadores de foguetes e granadas e disparando com rifles de assalto contra os moradores da cidade" (MARK, 2015). Silêncio, um silêncio punitivo, um silêncio absoluto... tal foi a indiferença demonstrada pelo Estado nigeriano diante desse 
massacre dentro de suas próprias fronteiras, que um observador teria sido perdoado se pensasse que nunca ocorreu o massacre em Baga ou se imaginasse que Baga se localiza em qualquer outro lugar do planeta ou, talvez, que nem mesmo exista... Em verdade, este Estado já nem mesmo faz de conta que existe para servir a seus povos. ${ }^{1}$ Se alguém ainda está incerto sobre essa característica crucial, um lembrete do momento final da resposta da Nigéria aos massacres, que duraram uma semana, pode servir de ajuda: a despeito do silêncio sobre Baga, o Chefe de Estado do governo encontrou tempo e determinação para enviar uma mensagem de condolências ao Chefe de Estado francês, por conta dos assassinatos em Paris. Igualmente silencioso a respeito de Baga, outro oficial sênior do regime encontrou tempo e determinação para tuitar uma mensagem de condolências ao povo da França por conta dos assassinatos em Paris. Também não deveria causar surpresa o fato de que ninguém tenha marchado na Nigéria em nome dos 2 mil mortos de Baga, nem por suas famílias, nem tampouco por valores próprios de um Estado duvidoso. Já no que diz respeito à mídia mundial, as lentes de suas câmeras, durante aquela semana, estavam, obviamente, voltadas para quase $4.000 \mathrm{~km}$ de distância de Baga - em Paris.

Foi este foco da mídia mundial e algumas conseqüências ainda mais amplas que levaram Simon Allison, do Daily Maverick, a afirmar: "Podemos até estar no século XXI, mas as vidas africanas ainda são consideradas menos interessantes para a imprensa e, conseqüentemente, menos valiosas - do que vidas ocidentais" (SHEARLAW, 2015). Allison está, sem dúvida, fazendo alusão à catastrófica diminuição da humanidade africana pelo mundo Pan-Europeu (especialmente a Grã-Bretanha, França, Portugal, Bélgica e Espanha) durante os 400 anos da escravização dos povos africanos por estes europeus, e de sua conquista e ocupação da África. Contudo, como mostramos agora, este status inferido de "menor valor" das vidas africanas na contemporaneidade não se trata apenas de uma transposição teleológica de um passado de

1 Para um debate mais extenso acerca deste assunto, ver Herbert Ekwe-Ekwe, Readings from Reading: Essays on African Politics, Genocide, Literature, 2011. 
certo modo distante; ao contrário, trata-se de um conjunto e uma prática cuidadosa- e conscientemente definidos e formalmente disseminados muito mais recentemente, em meados da década de 1960, por um poder central não-tão-desconhecido nessa visceralmente subjugada história / política internacional africana.

\section{DIARQUIA}

Retornemos ao silêncio ensurdecedor em Baga. Tomando em consideração o passado e a história recorrente da Nigéria, alguém realmente espera que este Estado defenda Baga do Boko Haram, que comente ou lamente o assassinato de 2 mil pessoas de Baga - quase 49 anos depois do dia em que se promoveu o assassinato de 3.100.000 pessoas da etnia igbo em um genocídio cuidadosamente organizado, e que ainda está em curso? Cada um dos sete ex-chefes de governo nigerianos mencionados anteriormente é participante estruturador deste genocídio fundamental da África pós-conquista (europeia). O conjunto deles forma um septeto genocida. Esse genocídio, de uma só feita, configura a arquitetura do establishment nigeriano como o mundo a conhece atualmente. Assim, ninguém, de nenhuma esfera ou nível do funcionamento deste Estado, poderia ter nada inteligível e/ou crível a dizer sobre Baga. Parte do motivo para o silêncio nigeriano sobre Baga resulta do antecedente de genocídios do país; poucos teriam acreditado em qualquer declaração oficial sobre este massacre.

A Grã-Bretanha, ex-conquistadora/ invasora da Nigéria, apoiou o genocídio igbo desde sua concepção até a execução. Ao apoiar o genocídio, a Grã-Bretanha tentava "punir" os igbos por estarem na vanguarda, desde a década de 1930, do movimento para dar fim à ocupação britânica sobre a Nigéria - um dos mais preciosos territórios da conquista na África. Durante os anos de 1968/1969, que marcaram o terrivelmente devastador apogeu do genocídio, Harold Wilson, primeiro-ministro britânico, informou a C. Clyde Ferguson, coordenador especial do Departamento de Estado dos Estados Unidos para socorro à Biafra, de que ele, Harold Wilson, "aceitaria a morte de meio milhão de biafrenses se isto fosse necessário" para que a Nigéria destruísse a resistência 
igbo ao genocídio (MORRIS, 1977, p. 122). A saber, o desejo de "meio milhão de biafrenses mortos" de Wilson representava 4,2\% da população igbo naquele momento; à época em que aquela fase do genocídio chegou ao fim, 6 a 9 meses depois de sua declaração, $25 \%$ - ou 3.1 milhões - de igbo tinham sido assassinados pelos genocidas.

Sem dúvida, os nigerianos tinham satisfeito amplamente o desejo de Harold Wilson. As pungentes palavras do historiador Chancellor Williams foram eventualmente justificadas, mais dramaticamente: "[...] Os europeus também têm estado ocupados produzindo e treinando exércitos africanos. Africanos treinados para odiar, matar e conquistar africanos [...]" (WILLIAMS, 1987, p. 218). Na construção do modelo de relações internacionais que personificariam a era pós-Segunda Guerra Mundial, a diarquia genocida Grã-Bretanha/Nigéria elevou a "dispensabilidade da vida africana na política nacional e internacional" ao mais alto nível possível.

\section{O ESTADO DE QUEM?}

Inevitavelmente, a questão mais importante na mente de todos os pesquisadores sérios dedicados a este assunto é: O Estado na África - A quem pertence? Em um artigo conceitual difundido em janeiro de 2014, escrito pelo renomado filósofo e acadêmico da Faculdade Wellesley, Ifeany Menkiti, sobre o tema da conferência "John Rawls e a África", de onde foi extraída a citação acima, ele alude à afirmação mais popularmente referida, de Kwame Nkrumah, o estadista e filósofo ganense: "Busquem antes o reino político e todas as outras coisas virão a vocês" ${ }^{\prime 2}$ e aponta que, "Em retrospectiva, Nkrumah parece estar mais certo do que imaginou, porém, não pelas razões que ele imaginou". Eu não poderia concordar mais com professor Menkiti, e é sobre este pensamento, "porém, não pelas razões" que Kwame Nkrumah "imaginou", que eu gostaria de refletir neste artigo.

2 Para mais, disponível em: <http://www.utexas.edu/conferences/africa/ ads/1519a.html>, acesso em: 18 maio 2015. 
Em seu "Indicador Anual de Estados Falidos", levantamento feito pelo instituto de pesquisa Fundo para a Paz, sediado em Washington-DC, os países africanos, não surpreendentemente, têm a pior classificação em cada uma das 12 variáveis cruciais pesquisadas pelo Fundo; particularmente nas seis seguintes, com consequências esmagadoras e inescapáveis para as vidas e o bem-estar das pessoas:

1. Legitimidade do Estado;

2. Surgimento de uma elite fragmentada;

3. Violação crônica e continuada dos Direitos Humanos;

4. Desenvolvimento econômico desigual;

5. Declínio econômico severo e acentuado;

6. Movimentos massivos de refugiados ou povos internamente deslocados (FUND FOR PEACE, 2015).

Assim, os destaques relativos à África em uma das recentes pesquisas do Fundo se constituem em uma leitura deprimente, como segue: 16 dos "20 piores Estados" do planeta; 20 dos "30 piores Estados"; 34 (bem acima da metade dos países considerados soberanos no continente) dos "54 piores Estados" (FUND FOR PEACE, 2013) ${ }^{3}$. Diante destes dados, não é inconcebível que, neste nível de falência do Estado, nos próximos cinco anos, por volta do início da próxima década, 2020, "54 dos 54 piores Estados" do mundo possam estar na África!

Para fins deste trabalho, estas duas determinantes empíricas de falência estatal são realmente fundamentais: 1. a incapacidade do Estado em prover segurança; e 2. a incapacidade do Estado de fornecer serviços sociais essenciais. Elaboremos acerca de cada um deles:

1. A incapacidade do Estado para garantir segurança à sua população: essa situação pode ter emergido porque o Estado já não mais exerce controle sobre parte/partes ou sobre a totalidade de seu território. Fatores como os catastróficos colapsos nas relações políticas e econômicas

3 Ver Fund for Peace. The Failed States Index 2013, disponível em: <http://ffp. statesindex.org/ rankings-2013-sortable>, acesso em: 2 jun. 2015. 
internas vitais, rivalidades e fraturas intra-regime, invasão externa e ocupação territorial, e desastres naturais incontroláveis contribuiriam para a falência. Isto também poderia ocorrer por conta das violações dos direitos humanos da(s) pessoa(s) por parte do Estado, incluindo uma política deliberada de levar à destruição de uma ou mais de suas nações/povos/grupos religiosos, etc., constituintes.

2. A incapacidade do Estado de garantir serviços sociais essenciais (infraestrutura de comunicação, serviços de saúde, educação, moradia e lazer, desenvolvimento cultural) para seu(s) povo(s) ou a política deliberada do Estado de negar ou oferecer apenas parcialmente estes serviços para algumas de suas nações/povos/grupos religiosos... Esta falência pode ser conseqüência da diminuição dos recursos fiscais/materiais do Estado, ou simplesmente demonstração de incompetência em sua capacidade de administração. Por outro lado, esta incapacidade aponta para a desconcertante natureza da corrupção e para a norma amplamente institucionalizada de não-responsabilização do acesso e controle de finanças públicas por representantes do Estado e seus agentes.

Clapham (2000) afirmou que o conceito de "Estado falido" é "uma daquelas categorias que são determinadas a partir daquilo que não é, ao invés de ser aquilo que é". ${ }^{4}$ Isto é vital no discurso em que um Estado como a Nigéria ou o Sudão ou Ruanda, por exemplo, os quais conduzem genocídios contra sua população ou não proveem serviços básicos para seus povos ou que permanentemente criam regimes que sugam a riqueza coletiva do país, dificilmente podem se apoiar em tal definição [de Estado falido] nas Ciências Sociais. Tudo o que precisamos fazer para destacar a falha óbvia na aplicação deste conceito na África é refletir sobre

4 Ver Christopher Clapham, Failed states and non-states in the modern international order, artigo apresentado na Conferência sobre Estados Falidos, Florença, Itália, em abril 2000, disponível em: <http://www.ippu.purdue.edu/ failed_states/2000/papers/clapham.html>, acesso em: 15 maio 2015. 
o fato de que funções cruciais do Estado, tais como a provisão de segurança, aplicação da lei, uma estrutura administrativa racional porém flexível, responsabilidade e competição aberta e irrestrita, especialmente no que diz respeito à "mudança de regime", não têm sido postas em prática em nenhum Estado africano desde a conquista e ocupação da maioria do continente por uma constelação de países europeus no século XIX. Tragicamente, nos 59 anos desde que o movimento conjunto africano rumo à restauração de sua independência supostamente resultou na reviravolta no Sudão em $1956^{5}$, logo seguido por Gana em 1957, a situação na África não mudou muito no sentido de que estes atributos do Estado se tornassem realidade.

Nos últimos tempos, a maior limitação para o uso do conceito "Estado falido" para se referir à catastrófica situação na África contemporânea é que este termo confere uma presunção injustificável de racionalidade a uma empreitada na qual um espectro de resultados que vai de "falência" a "falência total e completa" a "desastre" é predeterminada. Presume-se que aqueles que governam o Estado na África (Obasanjo, Idi Amin, Taylor, Moi, Habre, Doe, Gowon, Mobutu, Ahidjo, Jonathan, Rawlings, Obote, Babangida, Mengistu, Abacha, Mugabe, dos Santos, Mohammed, Banda, Abubakar, Bokassa, Jammeh, Eyadema, Buhari, Toure, Museveni, Yar'Adua, Biya, Al-Bashier...) estejam cientes das expectativas da comunidade internacional e de suas minúcias analíticas e que, como qualquer participante racional, desejem alcançar sucesso... Se eles não conseguirem ser tão bem sucedidos, em algum nível, assim dita a lógica, eles tentarão melhorar suas notas anteriores e, espera-se, melhorar... Sucesso é sempre uma possibilidade! É com base nessa possibilidade que Roland Oliver conclui sua própria contribuição controversa para este debate. Se, por um momento, ignorarmos o racismo gratuito e o paternalismo incorporados na premissa da contribuição de Oliver, bem como a altamente contestável categoria analítica em que ela

5 NT: Em janeiro de 1956, o Sudão tornou-se independente dos governos britânico e egípcio, que administravam o país em parceria. 
está apoiada, e sobre a qual logo me debruçarei. Oliver (1991, p. 9) aponta:

Com seu problema populacional prevalente, a África dificilmente deverá alcançar níveis de desenvolvimento econômico de primeiro mundo no próximo século, i.e., no século XXI, porém, com apenas um pouco mais de responsabilidade a cada dia, [a África] poderia pelo menos recuperar a confiança, de modo a continuar sua penosa campanha em direção ao topo com mais sucesso.

Pelo contrário, há pouca indicação de que, nos últimos 59 anos, os governantes africanos tenham abordado a construção do Estado como um desafio, de modo a lograr transformar as vidas de seus povos. O "sucesso" nunca é um objetivo estabelecido na trajetória da missão desses governantes. Neste sentido, a conclusão de Oliver é, ironicamente, bastante otimista. Além disso, deve-se notar que, dadas as preocupações evidentemente limitadas em apenas "medir" o placar do desempenho, o discurso dos "Estados falidos" tende a negligenciar a turbulência muito mais extensa da história subjacente - o tipo de projeto que está sendo construído neste trabalho.

\section{RISCO DUPLO}

No ano de 2014, na Grã-Bretanha e em outros lugares da Europa, houve apaixonadas celebrações pela passagem de um século desde o início da guerra de 1914-1918, ou Primeira Guerra Mundial, ou grande Guerra. Notadamente, um tema recorrente que tem sido usado na mídia (e na academia) para caracterizar o papel da África nesta guerra é "oculto" ou "silencioso", até mesmo "desconhecido". Na verdade, houve um acadêmico que apareceu em um dos programas de atualidades da British Broadcasting Corporation $(\mathrm{BBC})$, que utilizou a bizarra frase "não verdadeiramente conhecido" ao descrever o "envolvimento africano". "Oculto", "silencioso", "não verdadeiramente conhecido" - por quem?!

Todo o continente africano perdeu um milhão de seus cidadãos lutando nessa guerra causada e levada a cabo principalmente pelos Estados europeus dominantes àquela época em fronts de batalha no leste da África, Camarões (oeste da África) e na própria 
Europa. Nessa tragédia incalculável, esses africanos, recrutados pelas várias potências que dominavam a África (Grã-Bretanha, França, Bélgica) lutaram em favor da Grã-Bretanha, França, Bélgica, da Rússia Czarista e de seus aliados contra a Alemanha, Itália, a Austro-Hungria, os Otomanos e seus aliados; do lado oposto desta frente de batalha, outros povos africanos dominados (recrutados pela Alemanha e Itália) lutaram pela Alemanha, Itália, AustroHungria, pelos Otomanos e seus aliados contra a Grã-Bretanha, França, Bélgica, a Rússia Czarista e seus aliados.

Fundamentalmente, esta foi uma guerra, assim como a guerra seguinte, de 1939 a 1945, na qual a África e os africanos não tinham motivo, qualquer que fosse, para se envolver. Os dois principais protagonistas em cada conflito, a Grã-Bretanha e a Alemanha, foram potências líderes dos Estados-invasores do mundo pan-europeu, que tinham ocupado a África formalmente desde 1885. Na verdade, deste grupo, a Grã-Bretanha foi o principal conquistador da África, tendo ocupado as valiosas terras do continente - terras com os maiores centros populacionais e vastas e múltiplas reservas de recursos naturais nas regiões central, do sul, leste e oeste: África do Sul, Namíbia e Tanzânia (onde exerceu controle por procuração após a guerra de 1918 - depois da derrota da Alemanha na I Guerra Mundial), Zimbábue, Botsuana, Suazilândia, Lesoto, Zâmbia, Quênia, Uganda. Gana, Serra Leoa e Gâmbia. A Grã-Bretanha também é o grande beneficiário dos 400 anos de escravidão dos povos africanos por este mesmo mundo de Estados pan-europeus, principalmente nas Américas, desde o século 15 d.C. (EKWE-EKWE, 2011).

Já no caso da Alemanha, do começo de 1904 ao fim de 1911, isto é, antes da guerra de 1914-1918, o país praticou os genocídios das etnias herero, nama e berg damara, em seu território, na Namíbia, no sudeste da África com o conseqüente resultado catastrófico: eliminou $80 \%$ dos hereros, 51\% dos namas e 30\% dos berg damaras (EKWE-EKWE, 2001, p. 37-38). Quanto à Bélgica - que fez parte da aliança anglo-francesa durante essa mesma guerra, e cujo ataque inicial pela Alemanha deflagrou de facto o conflito -, também entrou na guerra intra-europeia em 1914, depois de um recente período de 30 anos (1878-1908) de genocídio contra 
africanos na Bacia do Congo (África Central), o qual aniquilou 13 milhões de cidadãos. ${ }^{6}$

Obviamente, nada a respeito do papel da África e dos africanos neste conflito é "oculto" ou "desconhecido". Pelo contrário. O que vem sendo uma tarefa deveras difícil para os "guardiães" desta história (os quais têm sido, durante todo este tempo, incansáveis "racionalizadores" da conquista europeia e da ocupação da África) é como explicar o tão perverso papel de povos desesperadamente dominados lutando em uma guerra dos/por seus dominadores. Eu argumentei em diversos estudos ${ }^{7}$ (EKWE-EKWE, 1993, 2001) que dois acontecimentos críticos do século XX - as guerras de 19141918 e de 1939-1945 - abalaram os fundamentos cruciais defendidos por esses "racionalizadores" de maneira irreversível:

a) o Tratado de Versalhes de 1919, que marcou o fim da guerra de 1914-1918, liberou todos os povos europeus subjugados na Rússia, no Império Austro-Húngaro e no Império Otomano, enquanto os povos africanos na parte da África sob ocupação alemã (Namíbia, Tanzânia, Camarões, Togo, Ruanda, Burundi) não tiveram restaurada sua liberdade, mas foram, ao invés disso, ocupados pela Grã-Bretanha, França e Bélgica (ironicamente, estes dois últimos países mal resistiram ao Juggernaut ${ }^{8}$ alemão de 1914!);

b) os africanos da parte do continente majoritariamente ocupada pela Grã-Bretanha, França e Bélgica foram novamente recrutados, no começo do outono de 1939, para lutar contra a Alemanha na nova guerra que se iniciava, a despeito de a Alemanha ter, desde 1918, deixado de ser um dos dominadores/invasores da África;

6 Para mais sobre este assunto, ver, especialmente, a pesquisa múltipla feita pelo historiador e linguista, Isidore Ndaywel è Nziem, Histoire générale du Congo: de l'héritage ancien à la Republique Démocratique. [Paris: Duculot, 1998], p. 344. 7 Ver, sobre este assunto, African Literature in Defence of History, chap. 1 e EkweEkwe, Africa 2001: The State, Human Rights and the People, 1993, especialmente as partes I e II.

8 NT: "Juggernaut" é um termo alemão que significa "grande veículo", "caminhão", "jamanta"; aqui, no entanto, é usado figurativamente representando uma força irresistível, capaz de causar grande destruição. 
c) africanos da parte do continente majoritariamente ocupada pela Grã-Bretanha e pela França foram recrutados, no começo do outono de 1939, para lutar contra o Japão, nas florestas de Mianmar, apesar de os japoneses jamais tenham sido invasores/ocupantes da África;

d) a família real e o Estado belgas, incapazes de resistir por mais de três semanas ao ataque alemão em seu território, em maio de 1940, tiveram todo o financiamento do esforço de guerra belga (incluindo as despesas da família real e do governo, exilados em Londres), totalizando $£ 40$ milhões, pagos pelo Congo, sob ocupação belga, o mesmo Congo onde a monarquia e o Estado belgas assassinaram 13 milhões de pessoas no genocídio conduzido durante os 30 anos mencionado anteriormente;

e) milhares de africanos pereceram nos fronts de batalha do leste da África, da Europa e do sul da Ásia, lutando pelos conquistadores/invasores anglo-franco-belgas da África;

f) a restauração da independência africana no período pós-Guerra foi terminantemente rejeitada pelo primeiro-ministro britânico Winston Churchill, em discurso de novembro de 1942 ("Eu não me tornei o Primeiro-Ministro do Rei para presidir à liquidação do Império Britânico", enfatizou (FROM, 2009); em sua própria interpretação da "Carta do Atlântico", de agosto de 1941, formulada por ele e pelo presidente dos Estados Unidos Franklin Roosevelt, declara, inequivocamente: "todos os povos têm direito à autodeterminação";

g) de modo similar, Charles de Gaulle, líder das "Forças Francesas Livres", que estavam exiladas na Inglaterra desde a invasão alemã à França, em 1940, rejeitou a independência africana no pós-guerra, durante uma conferência global de governantes-invasores franceses em Brazzaville, no Congo, em 1944;

9 Fonte: From the archive: Mr Churchill on our one aim, The Guardian, London, 11 Nov. 2009. 
h) escrevendo no The Mail on Sunday (Londres, 23 de agosto de 2014), George Carey, um antigo arcebispo de Canterburry, recorda: "Este ano, nós somos lembrados, pela comemoração de duas guerras mundiais, que os valores de nossas tradições democráticas são preciosos. Nossos pais e avós... lutaram contra o totalitarismo, pela sobrevivência das virtudes democráticas". Claramente, a calorosa recapitulação de Carey não incorpora a participação africana, como nós destacamos aqui. O caráter assimétrico desta história é tal que, fora o Japão, a Rússia Czarista/ União Soviética e o Império Austro-Húngaro, a África tem estado amplamente sob a camisa-de-força de um totalitarismo sem paralelo, imposta desde 1885, por todos os Estados que compõem as duas linhas estratégicas de batalha que mapeiam as guerras de 1914-1918 e 1939-1945.

Observando os pontos 'f' e 'g' (acima), não é coincidência que a Grã-Bretanha deflagrasse duas guerras devastadoras contra duas nações africanas antes de finalizar sua ocupação da África, imediatamente no pós-guerra de 1939-1945: contra os gĩkũyũ ${ }^{10}$ no leste, na década de 1950, com o assassínio de dezenas de milhares de pessoas, incluindo membros de outras etnias; e na cooperação no genocídio igbo, no oeste da África, no qual participou juntamente com o Estado nigeriano, entre 1966-1970, levando ao assassinato de 3,1 milhões de igbos, ou 1/4 da população dessa nação. Ambos, gĩkũyũ e igbos, tinham encabeçado, respectivamente, a liberação do Quênia e da Nigéria da ocupação britânica.

A esta altura, já deveria estar evidente que, com uma análise mais ampla, não se pode falar em algo como história "oculta". Na verdade, o que alguns tentam fazer é ofuscar ou, pior, negar os fatos. Escrevendo "Sobre o Conceito de História", Benjamin (1940) argumentou que o "passado traz consigo um código secreto, através do qual é incitado à ressurreição"11. Benjamin (1940) apresen-

10 NT: Os gĩkũyũ, ou kikuyu (no idioma bantu), são o maior grupo étnico do Quênia.

11 Ver Walter Benjamin, Concepto $f$ history, disponível em: <https://www. marxists.org/reference/ archive/benjamin/1940/history.htm>, acesso em: 19 maio 2015. 
ta duas questões urgentes: "Nós não somos tocados pelo mesmo sopro de ar que tocou aqueles que vieram antes? Não existe, nas vozes às quais hoje emprestamos nossos ouvidos, um eco daqueles que foram silenciados?" Ele é intransigentemente direto em sua resposta:

[...] O Anjo da História deve ser exatamente assim. [Sua] face está voltada para o passado. O que nós enxergamos como uma cadeia de eventos, [o Anjo da História] avista como uma catástrofe única, a qual acumula incessantemente escombros sobre escombros e os arremessa diante de [seus] pés... nada do que já aconteceu deve-se crer perdido para a História. Na verdade, o passado apenas sobreviveria completamente para uma humanidade ressurreta. Dito de outra maneira: apenas para uma humanidade ressurreta, o seu passado, em cada um dos seus momentos, seria mencionável. Cada um dos momentos vividos torna-se uma citação à l'ordre du jour [ordinária] - e este dia é precisamente o dia do Juízo Final.

No cerne da tentativa de fabricar este fantasma de "História perdida", no que concerne à África e aos africanos, a inestimável percepção de Achebe (1990, p. 4) é a seguinte:

[A conquista europeia da África] pode ser, de fato, um assunto complexo, mas uma coisa é certa: você não invade, confisca a terra, a pessoa, a história do outro, e depois senta-se descansadamente e compõe hinos de louvor em sua honra. Fazer isto seria como chamar-se a si próprio de bandido; e ninguém há de fazer isso. Então, o que você faz? Você constrói elaboradas justificativas para sua ação. Você diz, por exemplo, que o homem em questão não tem valor nem capacidade para cuidar de si mesmo e de seus assuntos. Se existem coisas valiosas, como ouro e diamantes, que você está removendo do território, você prova que o homem não as possui no senso correto da palavra - que este homem e estes bens estavam tão somente por força do acaso no mesmo lugar quando você chegou. Finalmente, se o pior vier a acontecer, você pode muito bem estar preparado para questionar se ele, como você, pode ser completamente humano. Desde o momento em que nega a presença do homem que estava lá antes de você, você finda por questionar a própria humanidade deste homem... [Na] situação da [conquista europeia], presença era uma questão crítica, a palavra crucial. Sua negação era a chave desta ideologia [de conquista]. 
Assim, ao invés de ser uma fonte de relações que beneficiem seu povo, o Estado na África tem "evidentemente sido uma fonte de sofrimento", como afirmou Clapham (2000), um imaginário consistente com a descrição de Davidson (1992) do impacto deste Estado na humanidade africana como uma "maldição". Dowden (1987) também aplica uma metáfora relacionada à saúde para capturar o legado do Estado africano, quando aponta, aludindo a sua gênese: "[Este] trabalho [europeu] de cortar e colar [tem, de fato, causado] muito sangue e lágrimas [à África]. Partindo de sua própria observação, Lynn Innes não tem dúvida de que o Estado na África criou o que ela descreve como um "[resultado] profundamente doente" no continente (INNES, 1990, p. 151). A metáfora da saúde se estende até mesmo à psiquiatria, como observa Pakenham (1988): "Basta que se pense nas sangrentas... guerras que seguiram à descolonização para ver a loucura destas linhas desenhadas em mapas na Europa por homens ignorantes da geografia e da história africanas". Crocker (2003) aponta o problema fundamental do Estado na África.

Não é a ausência de nações; é a ausência de Estados com legitimidade e autoridade para lidar com suas questões [...] Assim, eles sempre obtiveram a maior parte, senão a parte dominante, de sua legitimidade no sistema internacional ao invés de consegui-la a partir da sociedade doméstica. (CROCKER, 2003, p. 37).

Esta é uma questão de alienabilidade que está no cerne desta grave crise.

Como muitas pessoas agora sabem, os Estados que a Europa criou na África, no rescaldo de sua Conferência de Berlim (Novembro de 1884 - Fevereiro de 1885), não conseguem prover as necessidades fundamentais dos africanos. Esses "Estados de Berlim"12, qualquer que seja seu "amaldiçoado" nome, não pode liderar os africanos em direção às mudanças reconstrutivas por que eles anseiam tão profundamente depois da trágica história de séculos de ocupação Na verdade, tais mudanças em favor dos

12 NT: "Estado de Berlim" é a forma como o autor se refere à série de países originados da partilha do continente africano feita por europeus e entre os colonizadores europeus na Conferência de Berlim. 
interesses africanos nunca foram no passado ou nos dias atuais os objetivos pretendidos para esse Estado. Do contrário, esse Estado, em sua forma atual, é um instrumento para a continuação da exploração dos recursos humanos e naturais africanos pelo mundo europeu e seus aliados. Em essência, o "Estado de Berlim" ainda serve aos interesses de seus criadores e àqueles da sociedade de supervisores-africanos que policiam o mau momento da existência que é a realidade dos africanos atualmente. Neste contexto, a insurgência do Boko Haram e dos grupos islamitas na África são apenas parte da crescente pressão sobre o "Estado de Berlim", ou o Estado africano pós-conquista europeia. Agora, poucos acreditam que o "Estado de Berlim" seja sustentável. Sua "essência" permanece, 130 anos depois de sua emergência, como continuação da conquista. Este é, precisamente, o porquê de esse Estado estar se destroçando, ao passo em que cada vez mais povos ou nações desejam proclamar sua independência de um Estado que eles consideram rudimentar, inorgânico e alienante. Certamente, o mundo terá que lidar com um mapa da África em constante mutação, baseado no resultado dos complexos movimentos de independência, originados profundamente no âmbito interno. Assim, deve-se deixar bem claro que a maioria destes movimentos não é islâmico, a despeito de toda a dramaticidade da política contemporânea!

Como demonstrado pelas potências conquistadoras europeias em Berlim, nos idos de 1884-1885, o Estado não é um presente dos deuses. Pelo contrário, o Estado é uma relação cuidadosamente formulada e construída por grupos de seres humanos no planeta Terra para perseguir interesses e aspirações imaginadas por estes mesmos seres humanos dentro de uma articulação histórica e geográfica. A humanidade africana está atualmente presa a uma grave crise por sobrevivência. É chegado o tempo de se abandonar o forçado "Estado de Berlim", para conseguir sobreviver. Este Estado é a ruína da existência africana. Nações africanas, nomeadamente, os igbo, ijo, wolof, ibibio, asante, baganda, bakongo, gĩkũyũ, bambara, luo, etc., permanecem como alicerce para a regeneração do novo desenvolvimento da África. Estas nações são a 
morada da criatividade intelectual e cultural do continente, dentre outros tipos de criatividade.

\section{CAMINHO PARA A CIVILIZAÇÃO - SE FOR NECESSÁRIO, QUE HAJA 1001 ESTADOS}

O que se está destacando aqui é que os povos africanos devem, eles mesmos, decidir acerca de sua soberania no período pós-"Estado de Berlim", mesmo que o resultado leve à criação de 1001 Estados na África - ou mais. Neste momento de liberdade, quaisquer povos africanos que, por exemplo, desejem estabelecer um futuro baseado nos preceitos de seus antepassados no século 12 d.C. ou mesmo muito antes, digamos, no século 8 a.C. , como alguns movimentos desejam fazer, têm o direito de alcançar este objetivo. Do mesmo modo, quaisquer povos africanos que acreditem que suas aspirações estão em trabalhar através dos desafios do século 21 e.C. e projetando objetivos de criatividade e transformações subseqüentes devem exercitar este direito. O direito à autodeterminação é de todas as pessoas. Ele é inalienável e garantido pela ONU. Nenhum povo, qualquer que seja ele, é dispensável do exercício desse direito. Eis o porquê de o slogan que proclama esta falácia ou a desconsideração dos fatos históricos defendendo a "indivisibilidade" / "indissolubilidade" / "indestrutibilidade" de um Estado, qualquer Estado, como se expressa, por vezes, em alguns círculos africanos, por exemplo, não vale o papel em que está escrito; exceto, é claro, pelo fato de que isto é um código embutido por uma horda de assassinos para que se planeje o próximo massacre ou para reforçar o terror de um genocídio em andamento...

Para que se alcance o(s) objetivo(s) de qualquer caminho estipulado não é necessário, contudo, que ninguém embarque no assassinato de alguém, ou que seja assassinado, como ocorre, por exemplo, na Nigéria, no Quênia, na Somália no Sudão, na República Central Africana, onde quer que seja. Para a sobrevivência futura da humanidade africana, não se permita que haja mais mortes no caminho para a ansiada civilização ou, em outras palavras, qualquer que seja a civilização que um povo escolha, que ela possa ser construída. Isto certamente pode ser conseguido 
e mantido sem o cometimento de nenhum crime, particularmente o genocídio - um crime contra a humanidade.

Tradução: Camila Alves da Costa e Sued Castro Lima

\section{REFERÊNCIAS}

ACHEBE, C. African literature as restoration of celebration. Kunapipi, v. 12, n. 2, 1990.

BENJAMIN, W. Concept of history. [S.l.], 1940. Disponível em: $<$ https://www. marxists.org/reference/archive/benjamin/1940/ history.htm>. Acesso em: 19 maio 2015.

CLAPHAM, C. Failed states and non-states in the modern international order. In: CONFERENCE ON FAILED STATES, Apr. 2000, Florence, Italy. Annals... Florence, Italy: IPPU/PURDUE, Apr. 2000. Paper presented. Disponível em: <http://www.ippu. purdue.edu/failed_states/2000/papers/clapham.html>. Acesso em: 15 maio 2015.

CROCKER, C. Engaging failing states. Foreign Affairs, p. 37, Sept./Oct. 2003.

DAVIDSON, B. Black man's burden: Africa and the curse of the nation-state. London: James Currey, 1992.

DOWDEN, R. Redrawing the outmoded colonial map of Africa. Independent, London, 10 Sept. 1987.

EKWE-EKWE, H. Readings from reading: essays on African politics, genocide, literature. Reading: African Renaissance, 2011.

African literature in defence of history. Reading: African Renaissance, 2001.

Africa 2001: the state, human rights and the people. Reading: International Institute for African Research, 1993.

FROM the archive: Mr. Churchill on our one aim. The Guardian, London, 11 Nov. 2009.

FUND FOR PEACE. The failed states index 2013. [S.1.], 2013. Disponível em: <http://ffp.statesindex.org/rankings-2013sortable>. Acesso em: 2 jun. 2015. 
The indicators. Disponível em: <http://ffp.statesindex. org/indicators>. Acesso em: 2 jun. 2015.

INNES, C. L. Chinua Achebe. Cambridge: Cambridge University, 1990.

MARK, Monica. Boko Haram's deadliest massacre': 2,000 feared dead in Nigeria. The Guardian, London, 10 Jan. 2015.

MORRIS, R. Uncertain Greatness: Henry Kissinger and American Foreign Policy. London: HarperCollins, 1977.

NDAYWEL È NZIEM, I. Histoire générale du Congo: de l'héritage ancien à la République Démocratique. Paris: Duculot, 1998.

OLIVER, R. The condition of Africa. Times Literary Supplement, London, 20 Sept. 1991.

PAKENHAM, T. The European share-out of the spoils of Africa. Financial Times. London, 15 Feb. 1988.

SHEARLAW, Maeve. Why did the world ignore the Boko Haram's Baga attacks?. The Guardian, London, 12 Jan. 2015

THE MAIL ON SUNDAY. London, 24 Aug. 2014.

WILLIAMS, C. The destruction of black civilization. Chicago: Third World, 1987. 